\title{
Value and cost effectiveness of double culture tests for diagnosis of ocular viral and chlamydial infections
}

\author{
S DAROUGAR, R M WOODLAND, AND P WALPITA* \\ From the Subdepartment of Virology, Institute of Ophthalmology, Judd Street, London WC1H $9 Q S$
}

SUMmaRY Swabbings from the eyes of 4132 patients attending ophthalmic casualty and outpatients clinics were tested for chlamydiae, adenovirus, and herpes simplex virus. Laboratory isolation tests gave positive results for one of these three agents in $696(16 \cdot 8 \%)$ cases. When a positive isolation was obtained, only $341(49 \%)$ agreed with the clinical diagnosis while $355(51 \%)$ either had no definite diagnosis marked on the request card or had been clinically diagnosed incorrectly. Routine testing of ocular specimens for all likely organisms can enable the correct treatment to be started sooner than doing one test at each visit, thereby reducing the number of times the patient has to visit the clinic and the expenses involved.

Adenovirus, herpes simplex virus (HSV), and Chlamydia trachomatis are common causes of conjunctivitis and keratoconjunctivitis. ${ }^{1}$ The clinical differential diagnosis of these ocular infections is difficult, particularly in the early stages of infections or in the absence of typical signs. ${ }^{2}$ In a recent study of acute conjunctivitis in an outpatient ophthalmic clinic in London it was found that in only $16 \%$ of cases was the clinical diagnosis correct as confirmed by laboratory tests. In this paper we present the results of double culture tests for $C$. trachomatis, $\mathrm{HSV}$, and adenovirus in 4132 unselected consecutive patients who attended the clinic because of conjunctivitis or keratoconjunctivitis. The value and cost effectiveness of the double tests in the diagnosis and management of these ocular infections are discussed.

\section{Materials and methods}

All specimens received in the laboratory during a period of 15 months from unselected consecutive cases of conjunctivitis or keratoconjunctivitis were included in this study. Conjunctival specimens were collected by swabbing and stored in 2SP transport medium ${ }^{3}$ at $-70^{\circ} \mathrm{C}$ until inoculated. Each specimen

\footnotetext{
*Present address: Department of Pediatrics, Division of Infectious Diseases, University of California, San Diego, La Jolla, California 92093, USA.
}

Correspondence to Professor S Darougar, Subdepartment of Virology, Institute of Ophthalmology, Judd Street, London WC1H9QS. was divided into two aliquots, one for culture for $C$. trachomatis and the other for adenovirus and HSV.

Cultures for $C$. trachomatis were performed with cycloheximide treated McCoy cells ${ }^{4}$ or McCoy cells pretreated with mitomycin-C (unpublished method).

For viral isolation the rapid culture test for adenovirus $^{5}$ and herpes simplex virus was used. ${ }^{6}$

\section{Results}

The results from the 4132 specimens tested and their respective clinical diagnoses are shown in Table 1. The total number of positive cultures was $696(17 \%)$; 341 of these positives were in tests specifically

Table 1 Isolation results compared with clinical diagnosis

\begin{tabular}{lrccc}
\hline & \multicolumn{4}{l}{ Laboratory diagnosis } \\
\cline { 2 - 5 } Clinical diagnosis & Total & $\begin{array}{l}\text { Chlamydia } \\
\text { No. }(\%)\end{array}$ & $\begin{array}{c}\text { Adenovirus } \\
\text { No. }(\%)\end{array}$ & $\begin{array}{c}\text { Herpes } \\
\text { No. }(\%)\end{array}$ \\
\hline Chlamydial & 804 & $88(10 \cdot 9)$ & $51(6 \cdot 3)$ & $7(0 \cdot 9)$ \\
Adenovirus & 909 & $21(2 \cdot 3)$ & $217(23 \cdot 9)$ & $14(1 \cdot 5)$ \\
Herpes simplex & 264 & $1(0 \cdot 4)$ & $3(1 \cdot 1)$ & $36(13 \cdot 6)$ \\
Herpes zoster & 2 & 0 & 0 & 0 \\
Bacterial & 45 & $1(2 \cdot 2)$ & $1(2 \cdot 2)$ & 0 \\
Allergic & 41 & $1(2 \cdot 4)$ & $1(2 \cdot 4)$ & 0 \\
Multiple or no & & & & \\
$\quad$ aetiological diagnosis* & 2067 & $45(2 \cdot 2)$ & $172(8 \cdot 3)$ & $37(1 \cdot 8)$ \\
Total & 4132 & $157(3 \cdot 8)$ & $445(10 \cdot 8)$ & $94(2 \cdot 3)$ \\
\hline
\end{tabular}

${ }^{*}$ This includes patients for which no diagnosis was given on the card and also those cards which indicated uncertainty between two or more possible diagnoses. 
Table 2 Comparison of laboratory diagnosis with provisional clinical diagnosis

\begin{tabular}{|c|c|c|c|c|}
\hline $\begin{array}{l}\text { Laboratory } \\
\text { diagnosis }\end{array}$ & $\begin{array}{l}\text { Number } \\
\text { positive }\end{array}$ & $\begin{array}{l}\text { Concordant } \\
\text { clinical } \\
\text { diagnosis } \\
(\%)\end{array}$ & $\begin{array}{l}\text { Discordant } \\
\text { clinical } \\
\text { diagnosis } \\
(\%)\end{array}$ & $\begin{array}{l}\text { Multiple or no } \\
\text { aetiological } \\
\text { diagnosis } \\
(\%)\end{array}$ \\
\hline Chlamydia & 157 & $88(56 \cdot 1)$ & $24(15 \cdot 3)$ & $45(28 \cdot 6)$ \\
\hline Adenovirus & 445 & $217(48 \cdot 8)$ & $56(12 \cdot 6)$ & $172(38 \cdot 7)$ \\
\hline Herpes simplex & $\times 94$ & $36(38 \cdot 3)$ & $21(22 \cdot 3)$ & $37(39 \cdot 4)$ \\
\hline Total & 696 & $341(48.9)$ & $101(14 \cdot 5)$ & $254(36 \cdot 5)$ \\
\hline
\end{tabular}

requested by the clinician. The double culture tests increased the number of positives by $355(104 \%)$.

A clinical diagnosis was indicated on the request card in only 2065 cases. C. trachomatis, adenovirus, or HSV was isolated from $442(22.4 \%)$ of these. Only $341(77 \cdot 2 \%)$ of these isolations agreed with the clinical diagnosis while in $101(22 \cdot 8 \%)$ cases the clinical diagnosis was shown to have been wrong (Table 2).

In 2067 cases no precise aetiological diagnosis was marked on the request card. Positive isolations were made in $254(12 \cdot 3 \%)$ of these (Table 1$)$.

\section{Discussion}

The inadequacy of relying on clinical diagnosis for ocular infections has been pointed out previously. ${ }^{2}$ The results presented here are generally in accord with those obtained by Wishart and colleagues ${ }^{2}$ and emphasise the difficulty in distinguishing between chlamydial, viral, bacterial, and allergic conjunctivitis solely on clinical grounds (Table 1). Of those specimens which gave a positive isolation result $51 \%$ had either been diagnosed incorrectly or had no definite clinical diagnosis (Table 2).

The clinical diagnosis which appears to have been most certain was that of HSV infection with lid or corneal lesions, as only four $(1.5 \%)$ cases which were clinically diagnosed as HSV were shown to be due to chlamydia or adenovirus. This is presumably because of the presence of typical signs of HSV in the cornea and/or lids. However, 58/94 (61.7\%) of HSV isolations were obtained from cases which were not recognised by the clinicians; $21(22.3 \%)$ being diagnosed as either chlamydia or adenovirus and 37 $(39.4 \%)$ diagnosed only as conjunctivitis. This is probably because HSV was not considered as a possible cause in the absence of typical lid or corneal lesions. Previous reports have shown that HSV can cause acute conjunctivitis without these 'typical' clinical signs. ${ }^{7}$

There appeared to be rather more confusion between chlamydial and adenoviral infections. Twenty-one of 157 (13\%) chlamydial isolations had been clinically diagnosed as adenovirus and 51/445 $(11 \%)$ of adenovirus isolations had been diagnosed as due to chlamydia. The confusion over the clinical diagnosis between chlamydial and adenovirus infections is due to the similarity of their clinical signs during the early stages of infection. ${ }^{2}$

In this study only $49 \%$ of the cases with positive isolations were correctly identified by the clinician, and the remaining $51 \%$ would have been missed unless the patients had further visits and tests so that a definite diagnosis could be made and the correct treatment given. Traditionally, a diagnostic laboratory performs only those tests requested by the clinician, who is encouraged to minimise costs by asking for a single test to confirm his diagnosis. Any specimens which arrive without some indication of the tests required must either be discarded or delayed while the clinician's intention is ascertained. In this series approximately half of the specimens tested did not have an accompanying clinical diagnosis, but it seems likely that if the clinician had been pressed to give one it would not have been any more accurate than those diagnoses given voluntarily.

This study included only specimens which had been sent to the laboratory for either chlamydial or viral diagnosis, so the number of specimens from conditions clinically diagnosed as bacterial or allergic is small. However, the results suggest that at least $5 \%$ of these may in fact be chlamydial or viral.

It may be argued that the expense of carrying out double tests on specimens from all patients is prohibitive. In an established laboratory we estimate that the cost in material and technician time of performing an extra culture test is about $£ 3.00$. The extra cost of performing double tests compared with single tests on 4132 specimens was therefore about $£ 12396$. Against this must be set the savings and benefits of more rapid diagnosis and management of the infections. It has been estimated that the direct and indirect costs of a visit to an outpatient clinic under the National Health Service is $£ 70$, and that the provision of adequate laboratory tests on the first visit of the patient to the clinic leads to an average saving of three follow-up visits to the clinic which would otherwise be needed before a definite diagnosis is made. ${ }^{2}$ In this study the testing of all specimens for both $C$. trachomatis and viruses led to the diagnosis of 355 extra cases, an improvement of $104 \%$. On this basis the average saving by provision of adequate laboratory tests for these extra positions amounted to $£ 74550$ ( $£ 210$ per patient). The net saving of performing the double culture tests was therefore about $f 62154$. To this we should add the benefits to the patients of better management by providing a positive or negative diagnosis for chlamydia, adenovirus, or HSV as the cause of an 
infection, and savings by reducing the number of outpatient visits and allowing the patients with negative tests to be discharged earlier than would otherwise be the case.

The testing of specimens for the three major causes of conjunctivitis during the first visit to the clinic is therefore a practical and comparatively inexpensive procedure which is of benefit both to the patient through the earlier start of the correct management including treatment and preventive measures, and to the health units by reducing the load on the clinic and limiting the number of follow-up visits required.

We thank Mr P Yearsley and Mr C K Yeo for assistance with the chlamydial and viral cultures. This work was supported by a grant from the Department of Health and Social Security through Moorfields Eye Hospital.

\section{References}

1 Darougar S. Rapid diagnosis and management of ocular viral and chlamydial infections. Proceedings of the 1985 International Symposium on Medical Virology in press.
2 Wishart PK, James C, Wishart MS, Darougar S. Prevalence of acute conjunctivitis caused by chlamydia, adenovirus, and herpes simplex virus in an ophthalmic casualty department. $B r J$ Ophthalmol 1984; 68: 653-5.

3 Gordon FB, Harper IA, Quan AL, Treharne JD, Dwyer RStC, Garland JA. Detection of chlamydia (bedsonia) in certain infections of man. I. Laboratory procedures: comparison of yolk sac and cell culture for detection and isolation. J Infect Dis 1969; 120: 451-62.

4 Ripa KV, Mardh PA. New simplified culture technique for Chlamydia trachomatis. In: Hobson D, Holmes KK, eds. Nongonococcal urethritis and related infections. Washington, DC: American Society for Microbiology, 1977: 323-7.

5 Darougar S, Walpita P, Thaker U, Viswalingam N, Wishart MS. Rapid culture test for adenovirus isolation. BrJ Ophthalmol 1984; 68: 405-8.

6 Walpita P, Darougar S, Thaker U. A rapid and sensitive culture test for detecting herpes simplex virus from the eye. $\mathrm{Br} J$ Ophthalmol 1985; 69: 637-9.

7 Darougar S, Hunter PA, Viswalingam N, Gibson JA, Jones BR. Acute follicular conjunctivitis due to $\mathrm{HSV}$ in London. $\mathrm{Br} J$ Ophthalmol 1978; 62: 843-9.

Accepted for publication 16 September 1986. 